\title{
Human Rod Photoreceptor cGMP-gated Channel: Amino Acid Sequence, Gene Structure, and Functional Expression
}

\author{
Ravinder S. Dhallan, ${ }^{2}$ Jennifer P. Macke, ${ }^{3,4}$ Roger L. Eddy, ${ }^{5}$ Thomas B. Shows, ${ }^{5}$ Randall R. Reed, ${ }^{1,3,4}$ \\ King-Wai Yau, ${ }^{1,3}$ and Jeremy Nathans ${ }^{1,3,4}$ \\ ${ }^{1}$ Howard Hughes Medical Institute, ${ }^{2}$ Department of Biomedical Engineering, ${ }^{3}$ Department of Neuroscience, and \\ ${ }^{4}$ Department of Molecular Biology and Genetics, Johns Hopkins University School of Medicine, Baltimore, Maryland 21205 \\ and ${ }^{5}$ Department of Human Genetics, Rosewell Park Cancer Institute, Buffalo, New York 14263
}

\begin{abstract}
Phototransduction in retinal rods involves a G-protein-mediated signaling cascade that leads to cGMP hydrolysis and the closure of a cGMP-gated channel. This channel has recently been purified from bovine retina and molecularly cloned (Kaupp et al., 1989). We report here the cloning of cDNA and genomic DNA encoding the human rod cGMP-gated channel, based upon its homology to the bovine counterpart. The human mRNA structure differs from the bovine in containing an Alu repetitive element spliced into the $5^{\prime}$ untranslated region. The human cGMP-gated channel gene (CNCG) is located on chromosome 4 and contains at least 10 exons. One large exon encodes the carboxy-terminal two-thirds of the protein, whereas seven small exons encode the aminoterminal one-third of the protein. Alternative splicing removes one of the small exons in a subset of transcripts in the human retina, producing an internal in-frame deletion of 36 codons. When expressed in a human embryonic kidney cell line (2935), the full-length cDNA clone, but not the differentially spliced variant, produced functional ion channels broadly similar to the native channels in vertebrate rods.
\end{abstract}

Retinal photoreceptors respond to light with a membrane hypcrpolarization, generated by the closure of cGMP-gated channels (for review, see Yau and Baylor, 1989). In darkness, a fraction of the channels are open due to a steady level of cytoplasmic cGMP, thus sustaining a continuous influx of cations into the outer segment of the cell. Light activates a G-proteinmediated signaling cascade that leads to the activation of a cGMP phosphodiesterase and hence the hydrolysis of cGMP, causing the channels to close (for review, see Pugh and Cobbs, 1986; Stryer, 1986). This cGMP-gated channel is unusual in that it is the first example of a ligand-gated channel that utilizes a cyclic nucleotide for activation (Fesenko et al., 1985; Haynes and Yau, 1985). Since its discovery, similar channels have been reported in other cell types, with a close relative being the cyclic nucleotide-gated channel involved in olfactory transduction

\footnotetext{
Received Jan. 28, 1992; revised Mar. 18, 1992; accepted Mar. 25, 1992.

This work was supported by the Howard Hughes Medical Institute (R.R.R., K.-W.Y., J.N.), The Retinitis Pigmentosa Foundation (J.M., J.N.), and NIH Grants EY 06837 (K.-W.Y.), HD05196, and HG 00333 (R.L.E., T.B.S.). We thank Ms. $\mathrm{Y}$. Wang for providing the human genomic DNA library, and Dr. C. Riley, A. Collector, and C. Waldron for synthetic DNA.

Correspondence should be addressed to Dr. Jeremy Nathans or Dr. King-Wai Yau at the above address.
}

Copyright (c) 1992 Society for Neuroscience $0270-6474 / 92 / 123248-09 \$ 05.00 / 0$
(Nakamura and Gold, 1987; see also Dhallan et al., 1990; Ludwig et al., 1990).

A major step in understanding the biology of these channels was the successful isolation of cDNA clones encoding the bovine rod channel (Kaupp et al., 1989). The deduced primary structure of the bovine rod channel has 690 amino acids, and has a domain near the carboxy terminus that bears substantial homology to each of the cGMP-binding domains in cGMP-dependent protein kinases. In addition, a region homologous to the voltagesensing domain in voltage-gated channels has been identified (Jan and Jan, 1990), even though the rod cGMP-gated channel shows no evidence of voltage gating in the absence of ligand. This feature suggests that the CGMP-gated channel and voltagegated channels may share a common ancestry. When synthetic message derived from the bovine clone was injected into Xenopus oocytes, functional channels were observed with physiological properties quite similar to the native channel (Kaupp et al., 1989). Based on the Hill coefficient of activation by cGMP, which can be over 3 , the number of subunits is likely to be at least four. Thus, it appears that an oligomer composed of several identical subunits can form a functional channel.

In this article, we report the cloning of cDNA and genomic DNA and the functional expression of cDNA encoding the rod cGMP-gated channel from human retina. Our motivation for this work is twofold. First, the intron-exon structure of the gene may provide clues to the evolution of this class of channels, and may direct a search for differentially spliced variants as seen in the Shaker potassium channels (Kamb et al., 1988; Schwarz et al., 1988). Second, recent work has shown that some inherited retinal discases are caused by mutations in genes encoding phototransduction or structural proteins of the rod outer segment, including rhodopsin (Dryja et al., 1990, 1991; Sung et al., 1991), the $\beta$-subunit of cGMP phosphodiesterase (Bowes et al., 1990; Pittler and Baehr, 1991), and peripherin/rds (Travis et al., 1989; Farrar et al., 1991; Kajiwara et al., 1991). It seems reasonable to suppose that sequence variation in the rod cGMP-gated channel exists in the human gene pool, and that some variants may produce a functional alteration. The results reported here lay the groundwork for future experiments aimed at identifying and analyzing inherited defects in the human rod cGMP-gated channel.

\section{Materials and Methods}

cDNA clone isolation. PCR primers corresponding to nucleotides -49 to -27 and the reverse complement of nucleotides $2139-2166$ of the 
bovine rod cGMP-gated channel (Kaupp et al., 1989) were used to amplify the coding region of the bovine channel from a bovine retina cDNA library (Nathans and Hogness, 1983) and the resulting fragment cloned in Bluescript KS (Dhallan et al., 1990). The coding region of the bovine channel was used as a probe to screen $5 \times 10^{\mathrm{s}}$ recombinants from an adult human retina cDNA library (Nathans et al., 1986). Approximately 50 strongly hybridizing clones were identified and analyzed for insert size and structure, and the 5 longest clones were selected for detailed analysis. Comparison of the partial nucleotide sequences of these clones to that of the bovine channel cDNA showed that all five were lacking the $5^{\prime}$ end. An oligonucleotide, $\mathrm{KY} 2$, corresponding to nucleotides 348-371 in Figure 1 and derived from the $5^{\prime}$ end of one of the clones, was used as a probe to rescreen $10^{6}$ recombinants from the retinal cDNA library by the method of Wood et al. (1985). Thirty clones were identified and the six largest were analyzed further. Although all six were longer than the previously isolated clones, none were full length based upon a comparison with the bovine sequence. Therefore, a second oligonucleotide, KY 12, corresponding to nucleotides 68-97 in Figure 1 and derived from the $5^{\prime}$ end of one of the clones, was used to rescreen $2 \times 10^{6}$ recombinants from the retinal cDNA library as described above. Twelve clones were analyzed in detail, and one was found to contain the $5^{\prime}$ end of the human rod cGMP-gated channel cDNA. As this clone did not have the $3^{\prime}$ end, it was ligated to a $3^{\prime}$ proximal clone at the unique SphI site at nucleotide 100 (Fig. 1) to generate the full-length cDNA clone $\mathrm{hRcG}-1$. Both cDNA clones, as well as the final ligation product, were sequenced on both strands.

Genomic clones. The full-length cGMP-gated channel cDNA clone hRcG-1 was used as a probe to screen a Sau3A partial digest human genomic library in bacteriophage $\lambda E M B L 3$ (Frischauf et al., 1983). Genomic DNA was obtained from peripheral blood leukocytes from J.N., a male with normal vision. Recombinants gJHN101-gJHN108 were obtained in an initial screen at high stringency [hybridization: $5 \times$ salinesodium citrate (SSC), $50 \%$ formamide, $37^{\circ} \mathrm{C}$; washing: $0.1 \times \mathrm{SSC}, 0.1 \%$ SDS, $50^{\circ} \mathrm{Cl}$. Recombinant gJHN 109 , which encompasses exon 1 , was identified by hybridization with a probe encompassing nucleotides -370 to -256 within the $5^{\prime}$ untranslated region of $\mathrm{hRcG}-1$. Exons were mapped and sequenced using synthetic oligonucleotides derived from the hRcG1 sequence as hybridization probes and as primers for PCR and dideoxy sequencing.

RNA blot hybridization. Total RNA was prepared using the guanidinium-phenol method (Chomczynski and Sacchi, 1987) from five human retinas obtained within $12 \mathrm{hr}$ post-mortem. Formaldehyde/agarose gel electrophoresis and blotting were performed as described previously (Sambrook et al., 1989).

$P C R$ amplification from $c D N A$. First strand cDNA was synthesized

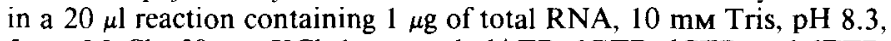
$5 \mathrm{mM} \mathrm{MgCl}_{2}, 50 \mathrm{~mm} \mathrm{KCl}, 1 \mathrm{~mm}$ each dATP, dGTP, dCTP, and dTTP, $50 \mu \mathrm{g} / \mathrm{ml}$ random sequence hexamers, and $10 \mathrm{U}$ of MoMLV reverse transcriptase (Bethesda Research Labs). The sample was incubated for $10 \mathrm{~min}$ at $23^{\circ} \mathrm{C}, 60 \mathrm{~min}$ at $37^{\circ} \mathrm{C}, 5 \mathrm{~min}$ at $99^{\circ} \mathrm{C}$, and then cooled to $4^{\circ} \mathrm{C}$. Following the addition of $80 \mu$ l containing $0.5 \mu \mathrm{M}$ each PCR primer, $10 \mathrm{~mm}$ Tris, $\mathrm{pH} 8.3,1.5 \mathrm{~mm} \mathrm{MgCl}_{2}, 50 \mathrm{~mm} \mathrm{KCl}$, and $2.5 \mathrm{U}$ of Taq DNA polymerase, the sample was subjected to 35 rounds of PCR amplification. PCR products were resolved by alkaline agarose gel electrophoresis (Sambrook et al., 1989) and transferred to GeneScreen Plus membrane (Du Pont) for oligonucleotide hybridization.

Synthetic DNA primers and probes. KY12, TTGAAAAGGAAATACGAAGGATGGAAAATG [base pairs (bp) 68-97]; KY61, GACTAATGGATCTTATAA (bp 569-586); JM14, GATCAGAATTCTTCCAGTGGATAATGATGACGATA (bp 906-929); JM23, GTGGTTATTGATCCCTC (bp 444-460); JM51, AGAAAGAAGAAGCATGTTTT (bp 428-437 and 546-555); JM52, CCTGGATCCATTGCACTTTTTAATGTG (bp 245-264); JM53, TTTGAATTCTTCCTTTACCAGCAGTCC (bp 667-684); JM66, AGCAAGTCAGATAATAAAAACGAAAAT (bp 328-354).

Chromosome mapping. Thirty mouse-human hybrid cell lines were derived by cell fusion and characterized by karyotype analysis and by enzyme markers of known map location (Shows et al., 1978, 1982, 1984). The presence or absence of the human CGMP-gated channel gene was determined by Southern blot hybridization to EcoRI-digested DNA prepared from each hybrid cell line

Expression and electrophysiology. The electrophysiological properties of the cloned channel were examined following transient transfection of the 293 human embryonic kidney cell line (Ámerican Type Culture Catalog CRL 1573; grown in $5 \% \mathrm{CO}_{2}$ in Dulbecco's Modified Eagle's
Medium with $10 \%$ fetal calf serum). A DNA fragment representing the complete channel clone was inserted into the polylinker site of pCIS, an expression vector containing a cytomegalovirus promotor, intron, polylinker, simian virus 40 (SV40), polyadenylation site, and SV40 origin of DNA replication (Gorman et al., 1990). To construct a cDNA corresponding to the differentially spliced transcript (i.e., lacking exon 8), a cloned PCR product derived from this transcript and encompassing part of exon 5, exons 6,7 , and 9, and part of exon 10 , was annealed to single-stranded DNA encoding the full-length cDNA and used to prime DNA synthesis under standard in vitro mutagenesis conditions. Mutant clones were identified by DNA sequencing, and from one of them a $525 \mathrm{bp} \mathrm{SphI} \mathrm{to} \mathrm{ClaI} \mathrm{restriction} \mathrm{fragment} \mathrm{encompassing} \mathrm{the}$ differentially spliced region was excised and inserted in place of the corresponding fragment of the full-length channel clone. The $525 \mathrm{bp}$ region derived from the in vitro mutagenesis reaction was sequenced to rule out spurious sequence changes. For channel production, 293 cells were transfected with a mixture of expression plasmid $(5 \mu \mathrm{g})$, carrier DNA (Bluescript, $10 \mu \mathrm{g}$ ), and SV40 T-antigen expression plasmid (RSV$\mathrm{TAg}, 0.5 \mu \mathrm{g}$ ) by the calcium phosphate method (Gorman, 1985).

Electrical recordings were performed $48 \mathrm{hr}$ after transfection using a List EPC-7 patch-clamp instrument at a bandwidth of DC $5 \mathrm{kHz}$. The recording pipettes were fabricated from borosilicate glass and had tip lumens of $\sim 1 \mu \mathrm{m}$. Seal resistance upon establishment of a membrane patch was typically of the order of $10 \mathrm{G} \Omega$. Solutions were pH 7.6, and contained $10 \mathrm{~mm}$ glucose plus the following components. Ringer's solution contained $140 \mathrm{~mm} \mathrm{NaCl}, 5 \mathrm{~mm} \mathrm{KCl}, 10 \mathrm{~mm} \mathrm{Na}$ HEPES, $2 \mathrm{~mm}$ $\mathrm{CaCl}_{2}$, and $1 \mathrm{~mm} \mathrm{MgCl}_{2}$. Ringer's solution without divalent cations contained $140 \mathrm{~mm} \mathrm{NaCl}, 5 \mathrm{~mm} \mathrm{KCl}, 10 \mathrm{~mm} \mathrm{Na}$ HEPES, and $0.5 \mathrm{~mm}$ $\mathrm{Na}$ EDTA. cGMP was applied to the bath using a solenoid-controlled rotary valve system (Nakatani and Yau, 1988).

\section{Results}

Isolation and sequence analysis of cDNA clones. To identify cDNA clones encoding the human rod cGMP-gated channel, an adult human retina cDNA library in bacteriophage $\lambda \mathrm{gt} 10$ (Nathans et al,, 1986) was screened using as probe the coding region of the previously isolated bovine homolog (Kaupp et al., 1989). Two overlapping clones encompassing the entire coding region were identified, sequenced, and joined together to produce a cDNA, hRcG-1, containing the entire coding region, 367 bases of the $5^{\prime}$ untranslated region, and 420 bases of the $3^{\prime}$ untranslated region (see Materials and Methods).

The nucleotide sequence of $h \mathrm{RcG}-1$ predicts an encoded protein sequence of 686 amino acids in length that is $91 \%$ identical to the bovine cGMP-gated channel (Fig. 1; Kaupp et al., 1989). The indicated initiator methionine codon corresponds to that assigned to the bovine channel, although the human sequence shows several in-frame ATG codons $5^{\prime}$ and $3^{\prime}$ of this position. Between nucleotides -217 and -15 , in the $5^{\prime}$ untranslated region, the human sequence contains a member of the Alu family of repetitive elements (Britten et al., 1988; Jurka and Smith, 1988). The orientation of this Alu element, as defined by the direction of transcription of Alu elements by RNA polymerase III, is opposite that of the cGMP-gated channel transcription unit. In aligning the human and bovine sequences, the Alu element appears as a simple insertion in the human sequence. On either side of the Alu element, human and bovine 5 ' untranslated sequences require two single nucleotide insertions for optimal alignment. In this $5^{\prime}$ untranslated region of 154 bases, the two nucleotide sequences are $80 \%$ identical.

Gene structure. To determine the structure of the human cGMP-gated channel gene, nine independent genomic clones were isolated from a Sau $3 \mathrm{~A}$ partial digest library in lambda phage EMBL3. Figure 2 shows the deduced chromosomal restriction map and the locations of the 10 exons identified within these clones, the precise boundaries of which are shown in Figure 1. With the exception of exon 2 , the gene was characterized by 
户ิ

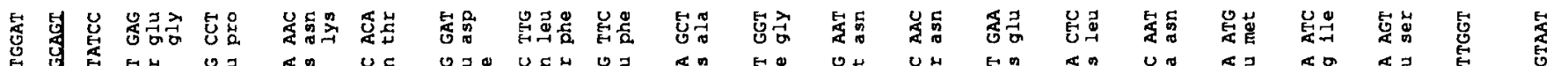

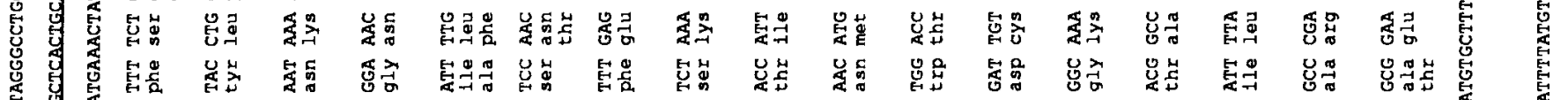

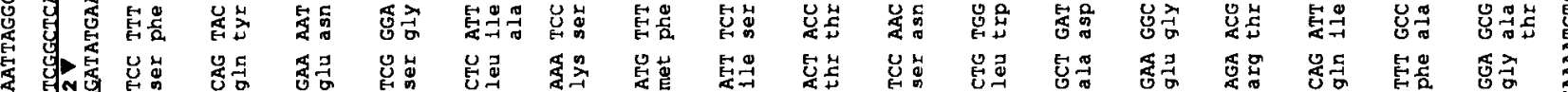

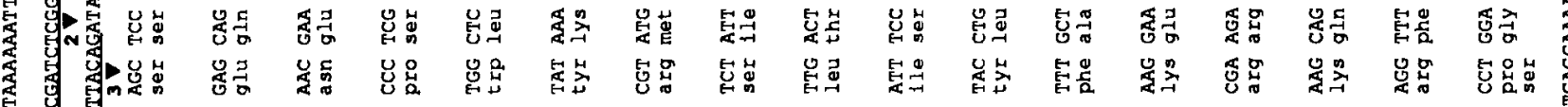

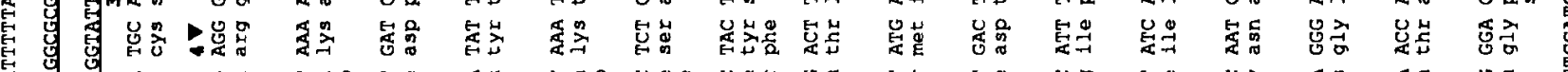

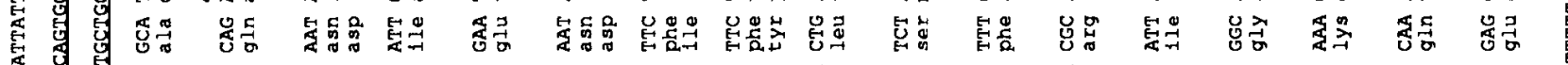

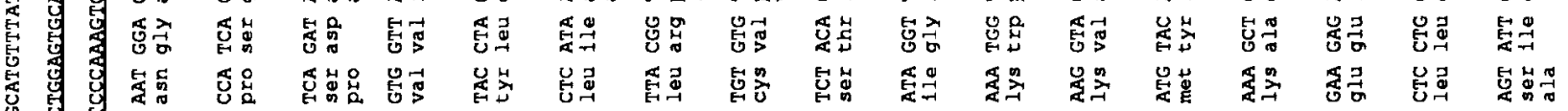

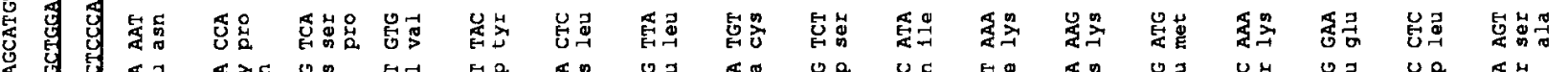

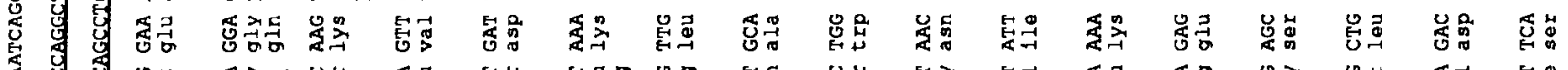

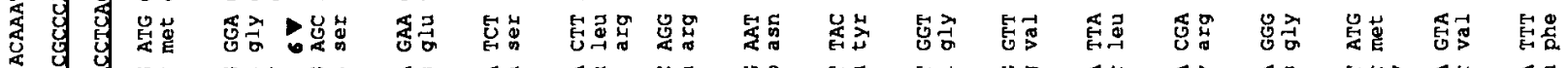

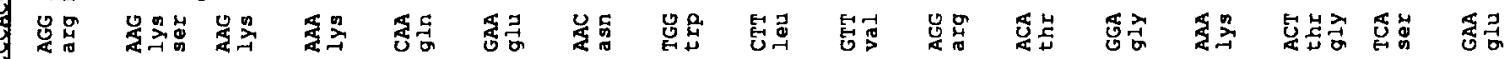

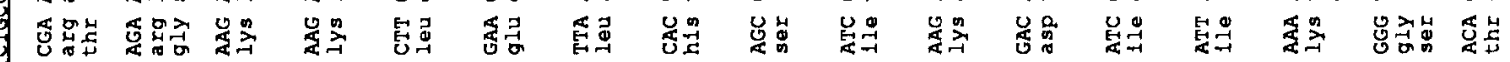

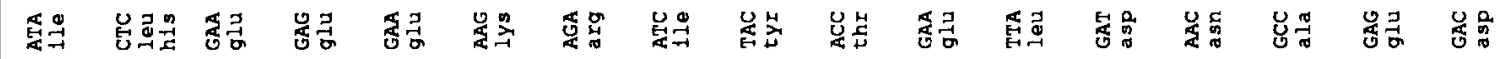

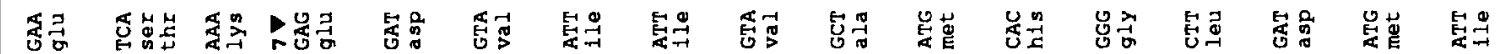

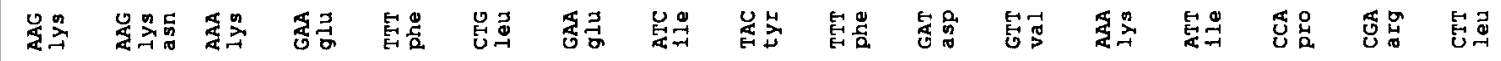

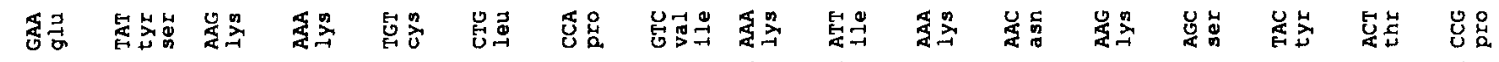

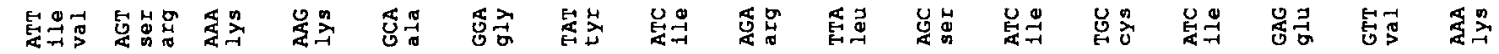

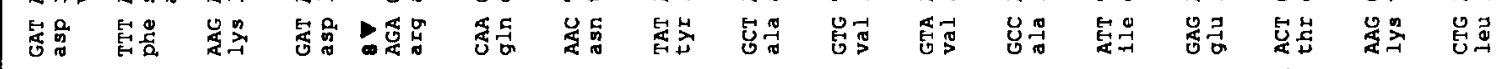

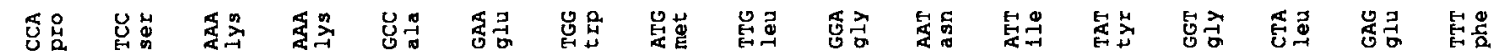

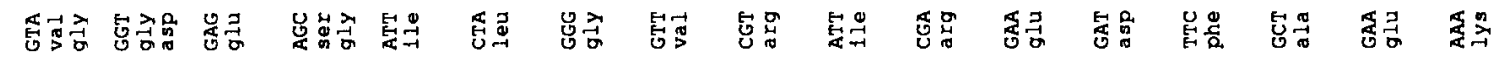

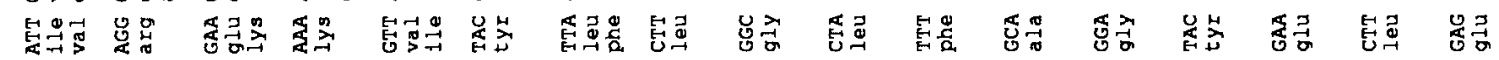

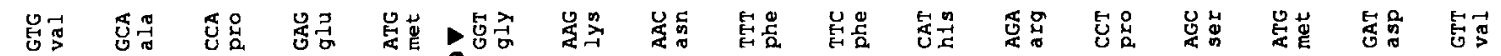

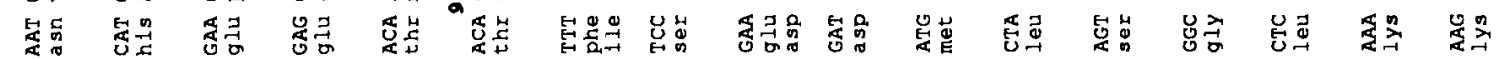

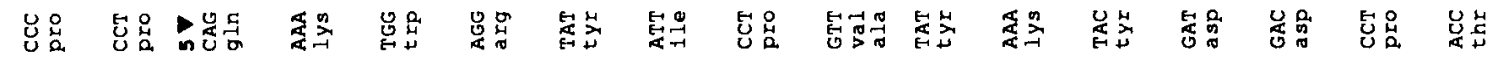

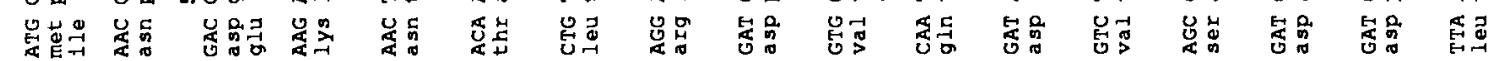

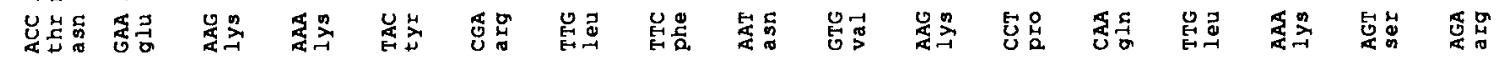

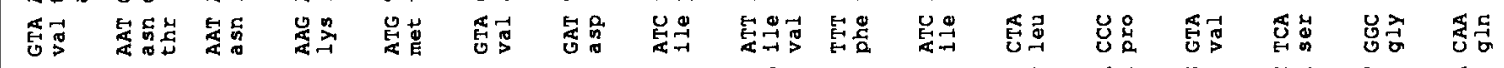

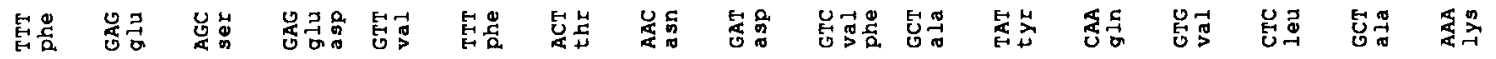

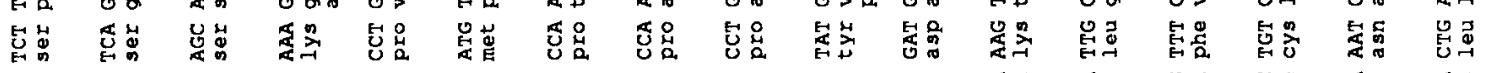
兴乐品

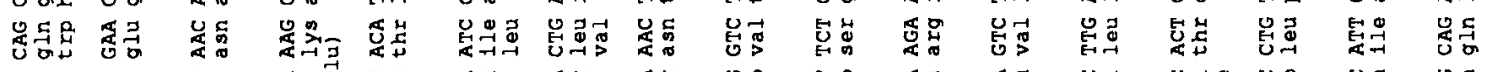

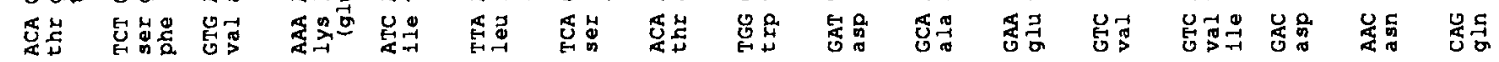

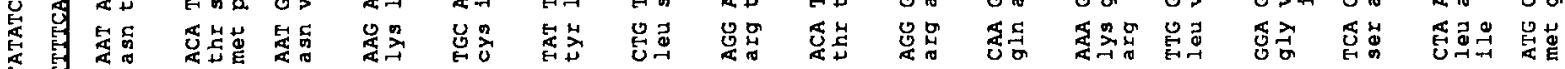

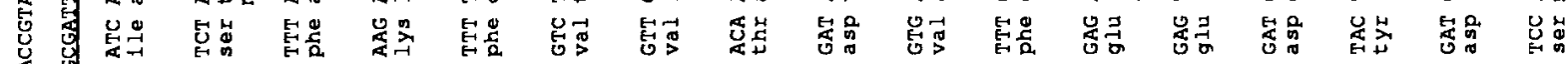

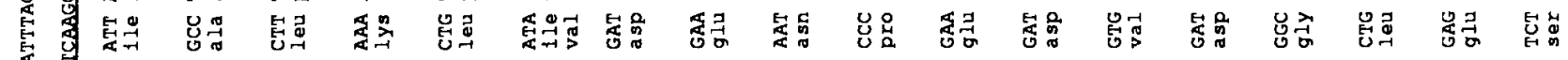

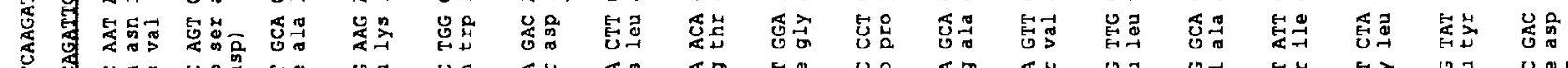

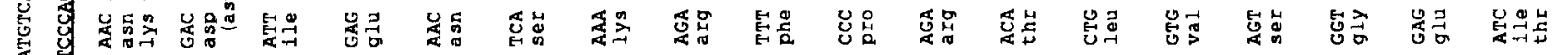

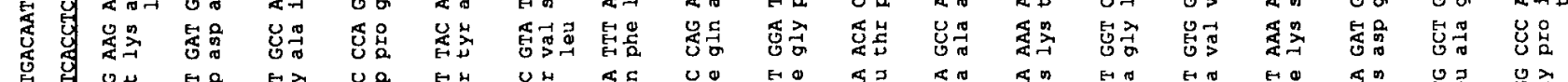

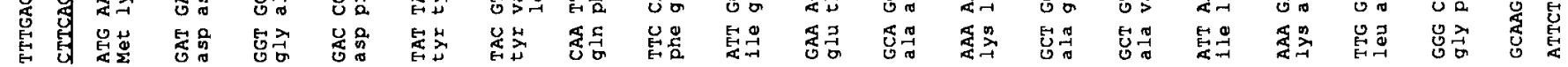




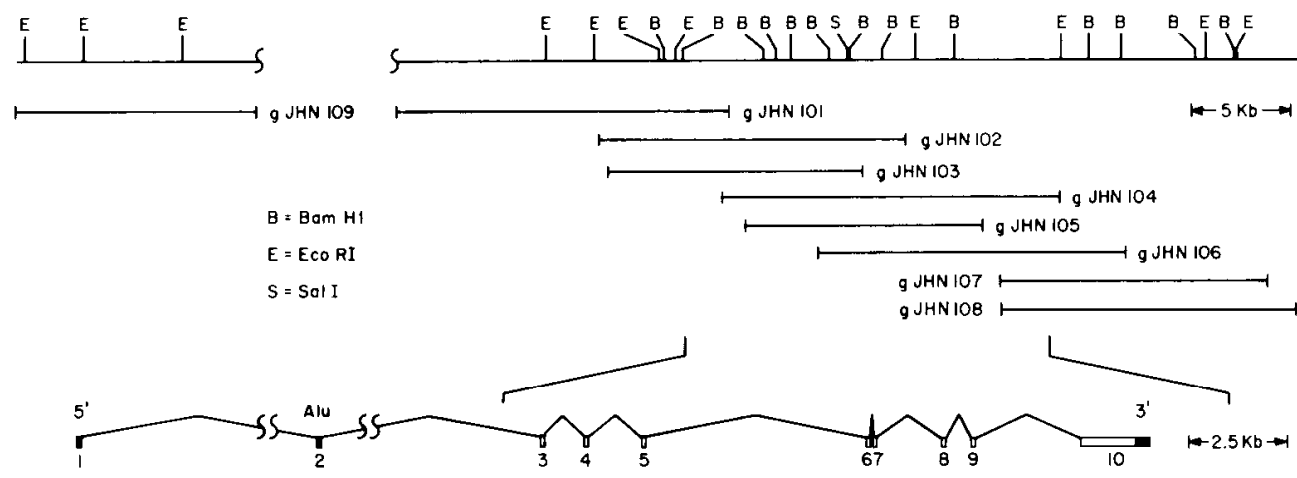

Figure 2. Human cGMP-gated channel gene structure. Top, Restriction maps of two discontinuous segments of chromosomal DNA encompassing exon 1 and exons 3-10. Center, gJHN101-gJHN108 denote genomic fragments isolated as recombinant lambda clones by hybridization with the full-length human cGMP-gated channel cDNA clone. $g J H N 109$ denotes a genomic fragment isolated by hybridization with a probe extending from nucleotide -375 to nucleotide -255 in the $5^{\prime}$ untranslated region. Bottom, Intron-exon structure of the cGMP-gated channel gene. Solid boxes, $5^{\prime}$ and $3^{\prime}$ untranslated regions; open boxes, coding region. The chromosomal segment containing the Alu element (exon 2 in the $5^{\prime}$ untranslated region) has not been isolated.

determining the sequence of each exon and of the adjacent 50 $100 \mathrm{bp}$ of flanking intron sequence. The sequences abutting each exon conform to consensus splice junction sequences (Table 1; Mount, 1982). The coding region resides within exons 3-10. Whole genome Southern blot hybridization and sequence analysis of additional clones obtained by low-stringency screening of a human genomic library demonstrate that the chromosomal locus described here has considerably greater homology to the bovine rod cGMP-gated channel than does any other segment of human DNA (R. S. Dhallan, J. Macke, R. R. Reed, K.-W. Yau, and J. Nathans, unpublished observations), further evidence that the cDNA and genomic DNA we have isolated encode the rod cGMP-gated channel.

The putative first exon resides on genomic clone gJHN 109 , which does not overlap the chromosomal region defined by clones gJHN101-gJHN108. Its distance from the gJIIN101gJHN 108 cluster is not known. This exon is tentatively assigned as the first exon in the gene because it contains the most 5'proximal sequences found in the cDNA clone $\mathrm{hRcG}-1$. However, the possibility exists that additional $5^{\prime}$ untranslated sequences could be located on exons upstream of this exon. These data imply that the transcription unit of the cGMP-gated channel genes is greater than 40 kilobases $(\mathrm{kb})$ in length.

The region within the $5^{\prime}$ untranslated region containing the Alu element appears to derive from one (or possibly more than one) exon. The cDNA sequence immediately 5 ' of the Alu element (exon 1) is followed in the genomic DNA by a consensus splice donor sequence, and the cDNA sequence immediately $3^{\prime}$ of the Alu element (exon 3 ) is preceded in genomic DNA by a consensus splice acceptor sequence. The Alu element is not present within the genomic clones shown in Figure 2, as determined by blot hybridization with oligonucleotide probes derived from it. Most likely, it resides within the gap between clone gJHN 109 and clones gJHN 101-gJHN 108.

Chromosomal localization. To determine the chromosomal location of the cGMP-gated channel gene, we determined whether it was present or absent from each of 30 mouse-human hybrid cell lines that carry defined subsets of human chromosomes. Only human chromosome 4 showed perfect concordance for the Southern blot hybridization signal derived from the human gene (Table 2).

Analysis of transcripts. The gene structure described above reveals eight coding region exons, six of which (exons 4-9) reside entirely within the coding region. Interestingly, five of these six internal coding region exons are multiples of 3 nucleotides in length. The probability of this occurring by chance, assuming that each intron-exon junction is equally likely to fall within the three reading frames, is 0.0165 . This pattern suggested the possibility that one or more of these coding region exons might be differentially spliced, a mechanism known to generate diversity in a number of other channel genes (Kamb et al., 1988; Schwarz et al., 1988; Timpe et al., 1988; Sommer et al., 1990).

As an initial step in examining transcript structure(s), RNA molecules homologous to the cGMP-gated channel were examined by Northern blotting. A single broad band centered at $3.5 \mathrm{~kb}$ was observed in total RNA from human retinas (Fig. 3). This result is consistent with the existence of a single major RNA species, but does not rule out rare variants of substantially different size or variants differing in size by less than $200 \mathrm{bp}$. With the latter possibility in mind, we PCR amplified segments of the cGMP-gated channel sequence using a first strand cDNA template synthesized by random priming of total human retina RNA and primers that were separated by several exons. In one reaction, using a primer pair derived from exons 5 and 10 (JM52 and JM14, respectively), two PCR products were obtained. The larger and more abundant product matched in size and sequence the corresponding region of $c D N A$ clone $h$ RcG-1. The smaller PCR product, which was typically present at $10 \%$ the abundance of the larger product, was found by DNA sequencing to be precisely missing exon 8 , an in-frame deletion of 108 bases (Fig.

$\leftarrow$

Figure 1. DNA and deduced amino acid sequence of the human rod photoreceptor cGMP-gated channel. The first nucleotide of the initiator methionine codon has been assigned position +1 . The third row of each line displays the protein sequence of the bovine rod channel (Kaupp et al., 1989); only differences are indicated. The bovine channel has four additional residues compared to the human channel; these are enclosed in parentheses. The positions of the nine introns in the human channel have been marked by solid triangles. The Alu element between nucleotides

-217 and -15 is underlined. 


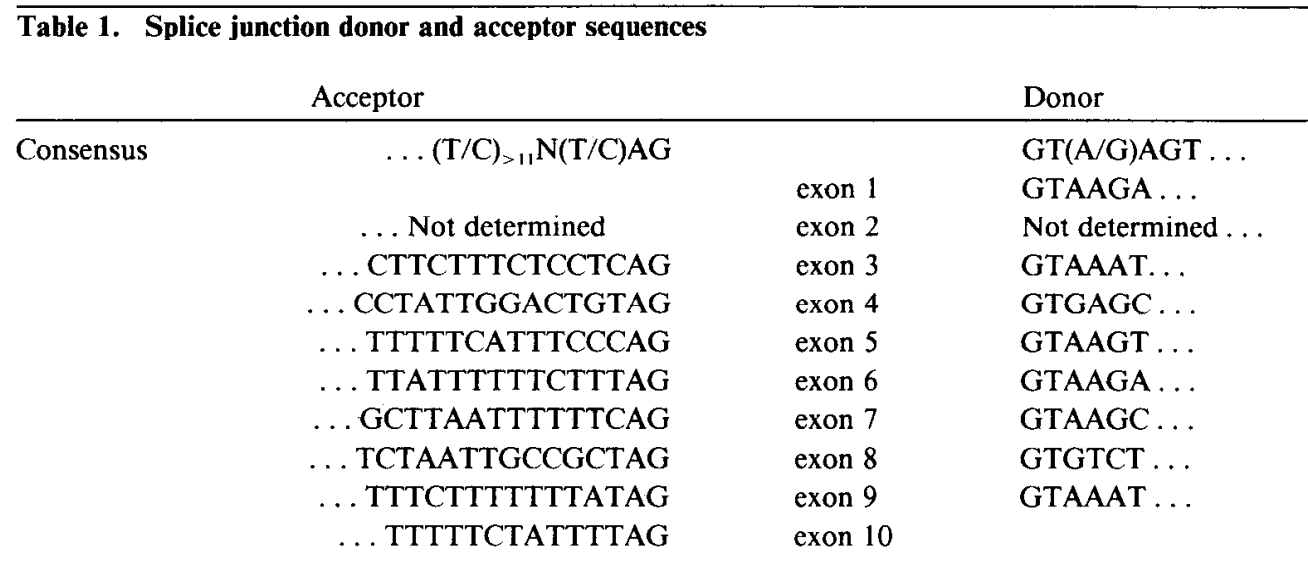

This table shows sequences at the boundaries of coding region exons. Sequences at the 5 ' and 3' boundaries of each exon are denoted "acceptor" and "donor," respectively. The consensus acceptor and donor sequences are from Mount (1982).

4). To confirm the presence of the two spliced forms among the original PCR products, synthetic oligonucleotides were hybridized to gel fractionated PCR products (Fig. 5). Probe JM53, located within exon 10 hybridized to both major and minor PCR products (Fig. 5A); probe JM23, located within alternatively spliced exon 8 , hybridized only to the major spliced product (Fig. 5B); and probe JM 51, a 20-mer that straddles the novel exon 7-exon 9 splice junction, hybridized to the minor splice

Table 2. Segregation of the human cGMP-gated channel gene with human chromosomes in mouse-human hybrid cell lines

\begin{tabular}{|c|c|c|c|c|c|}
\hline \multirow{2}{*}{$\begin{array}{l}\text { Chromo- } \\
\text { some }\end{array}$} & \multicolumn{2}{|c|}{$\begin{array}{l}\text { No. of concordant } \\
\text { hybrids }\end{array}$} & \multicolumn{2}{|c|}{$\begin{array}{l}\text { No. of discordant } \\
\text { hybrids }\end{array}$} & \multirow{2}{*}{$\begin{array}{l}\text { \% Dis- } \\
\text { cordancy }\end{array}$} \\
\hline & $(1 / 1)$ & $(1)$ & $(+1-)$ & $(-1+)$ & \\
\hline 1 & 0 & 19 & 7 & 1 & 30 \\
\hline 2 & 3 & 16 & 7 & 5 & 39 \\
\hline 3 & 5 & 12 & 5 & 8 & 43 \\
\hline 4 & 10 & 21 & 0 & 0 & 0 \\
\hline 5 & 7 & 10 & 3 & 11 & 45 \\
\hline 6 & 4 & 15 & 6 & 6 & 39 \\
\hline 7 & 8 & 11 & 2 & 9 & 37 \\
\hline 8 & 6 & 10 & 4 & 11 & 48 \\
\hline 9 & 0 & 18 & 9 & 2 & 38 \\
\hline 10 & 7 & 6 & 3 & 15 & 58 \\
\hline 11 & 6 & 10 & 4 & 10 & 47 \\
\hline 12 & 5 & 11 & 5 & 10 & 48 \\
\hline 13 & 3 & 13 & 7 & 8 & 48 \\
\hline 14 & 5 & 6 & 5 & 15 & 65 \\
\hline 15 & 5 & 13 & 5 & 8 & 42 \\
\hline 16 & 3 & 18 & 7 & 3 & 32 \\
\hline 17 & 7 & 5 & 2 & 15 & 59 \\
\hline 18 & 8 & 12 & 2 & 9 & 35 \\
\hline 19 & 3 & 18 & 7 & 3 & 32 \\
\hline 20 & 7 & 11 & 3 & 10 & 42 \\
\hline 21 & 7 & 9 & 3 & 12 & 48 \\
\hline 22 & 1 & 14 & 9 & 7 & 52 \\
\hline$x$ & 8 & 11 & 2 & 9 & 37 \\
\hline
\end{tabular}

These data show chromosomal localization of the human cGMP-gated channel gene. The presence $(+)$ or absence $(-)$ of each human chromosome and the presence $(+)$ or absence $(-)$ of the Southern blot hybridization signal was scored for each of 30 mouse-human hybrid cell lines. Only chromosome 4 shows a $0 \%$ discordancy, indicating a matched segregation of the DNA probe with this chromosome. product. Interestingly, in the PCR reaction using total retina cDNA (Fig. 5C, lane 3), JM51 also hybridized to a larger molecular weight species that appears to be distinct from the major splice product, given that the cloned major splice product in lane 1 of Figure $5 C$ does not hybridize under these conditions.

Electrophysiology of the expressed channel. The electrophysiological properties of the channel protein encoded by the hRcG-1 clone were examined by transient expression in the 293 human embryonic kidney cell line (see Materials and Methods). Insideout patches of plasma membrane were excised from transfected cells and tested for sensitivity to bath-applied cGMP. A cGMPinduced current could be observed from approximately $30 \%$ of these membrane patches $24-48 \mathrm{hr}$ after transfection. Figure 6 shows the relation between normalized current activation and cGMP concentration obtained from one of these patches. It gives a Hill coefficient of 2.7 and a half-saturating cGMP concentration $\left(K_{1 / 2}\right)$ of $80 \mu \mathrm{M}$. From five patches, the $K_{1 / 2}$ was 86 $\pm 18 \mu \mathrm{M}$ (mean $\pm \mathrm{SD}$ ) and the Hill coefficient was $2.0 \pm 0.6$. These values are broadly consistent with those previously found for the native channel in amphibian and mammalian species (Luhring and Kaupp, 1989; Yau and Baylor, 1989), as well as with the cloned bovine channel expressed in Xenopus oocytes (Kaupp et al., 1989).

The current-voltage relation obtained at saturating cGMP concentration ( $1 \mathrm{~mm}$ ) and with symmetrical Ringer's solutions without divalent cations is shown in Figure $7 A$. The relation is almost linear, with the slight upward curvature probably reflecting a small increase in the open probability of the liganded channel at positive voltages, as has been described for the native channel (Karpen et al., 1988; Haynes and Yau, 1990). Figure $7 B$ shows the current-voltage relation, from a different patch, with Ringer's solution containing divalent cations in the patch pipette and Ringer's solution without divalent cations in the bath. Again, as with the native rod channel, the relation shows pronounced outward rectification under these conditions, reflecting a voltage-dependent block by divalent cations (see Yau and Baylor, 1989). In the absence of divalent cations, singlechannel openings induced by cGMP could also be observed (Fig. 7C). The prominent openings showed a conductance of approximately $30 \mathrm{pS}$, which is broadly similar to that found for the native channel in other vertebrate species (Yau and Baylor, 1989). However, as with the expressed bovine channel (Kaupp et al., 1989), the distribution of open times appeared to have more than one mode. Some of the openings were very brief, 


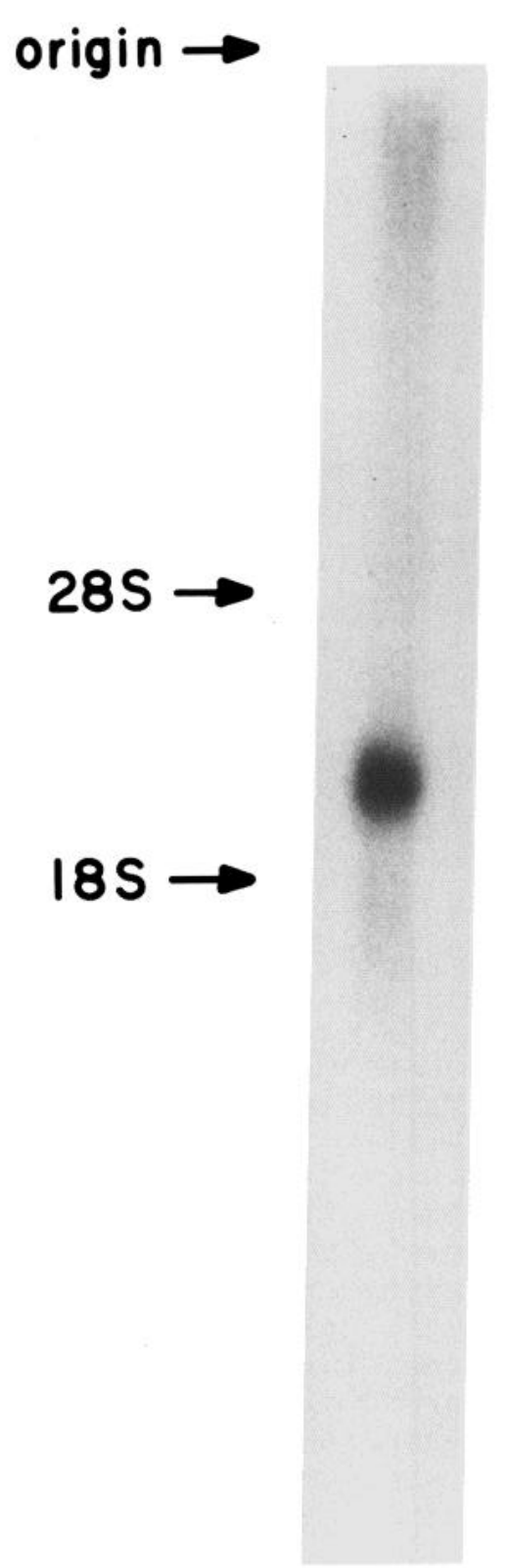

Figure 3. Blot hybridization of cGMP-gated channel mRNA from human retina. Ten micrograms of total human retina RNA were fractionated on a formaldehyde/agarose gel, and hybridized with a probe extending from nucleotide 854 to nucleotide 1368 of the cGMP-gated channel cDNA clone. The electrophoretic mobility of $28 \mathrm{~S}(6.3 \mathrm{~kb})$ and $18 \mathrm{~S}(2.4 \mathrm{~kb})$ ribosomal RNAs are indicated. The hybridizing species is centered at $3.5 \mathrm{~kb}$.

lasting on the order of $1 \mathrm{msec}$ like the native channel, while other openings were extremely long, lasting many tens of milliseconds, a feature not observed with the native channel. The reason for this striking difference between native and expressed channels remains to be examined. We have also examined 293 cells transfected with the cDNA clone corresponding to the minor transcript that is missing exon 8 . From 30 excised membrane patches from transfected cells, no cGMP-induced current was observed.

\section{Discussion}

The experiments reported here establish the amino acid sequence of the human rod cGMP-gated channel, the chromo-
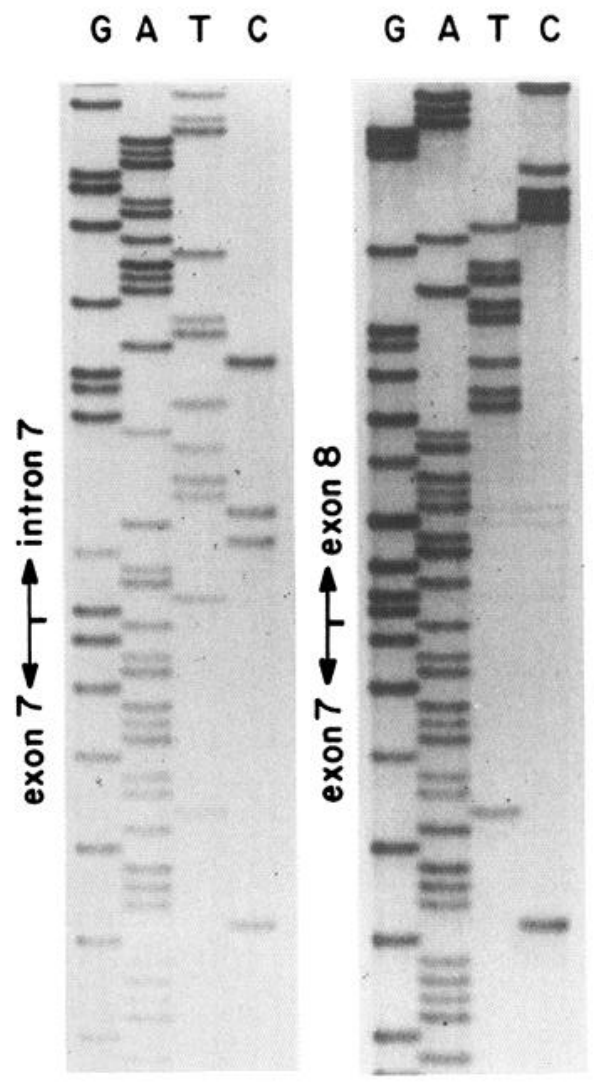

G A T C

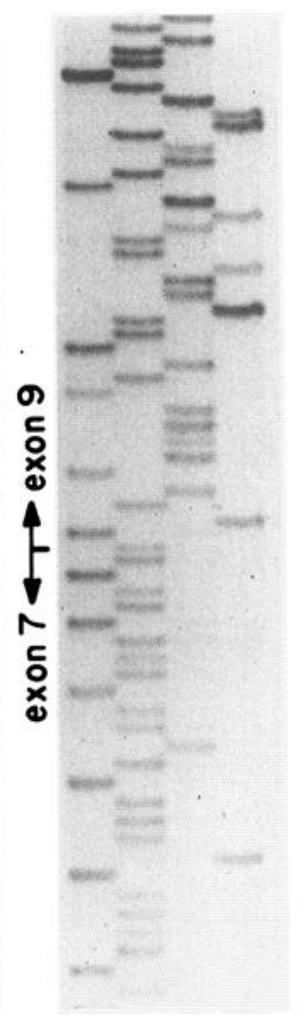

Figure 4. Nucleotide sequences across the differentially spliced exon $73^{\prime}$ boundary. Templates: left, a $3.5 \mathrm{~kb}$ EcoRI-SalI subclone derived from genomic clone gJHN105; center, cloned cDNA phCG1 corresponding to the major spliced RNA species; right, cloned cDNA corresponding to the minor spliced RNA species generated by PCR amplification of first strand cDNA using primers KY12 and KY61, which prime in exons 3 and 9, respectively. The template used for sequencing of the minor splice product (right) was produced by first incorporating the minor spliced PCR product into the expression plasmid (see Materials and Methods). The sequencing primer for each reaction was JM66 (in exon 7).

somal localization and the intron-exon arrangement of the gene that encodes it, the existence of a variant RNA generated by differential splicing, and the functional properties of the recombinant channel. Three lines of evidence support the identification of this cloned channel as that of human rod photoreceptors: first, the expressed protein has the appropriate physiological properties; second, the corresponding gene is more homologous to the bovine rod channel cDNA than is any other segment of human DNA; and third, mRNA transcribed from this gene is present in human retinas.

The human cGMP-gated channel and its bovine homolog are $91 \%$ identical at the amino acid level, with the greatest divergence residing in the amino terminal 92 amino acids that are posttranslationally cleaved from the bovine channel (Molday et al., 1991). Within the mature polypeptide (amino acids 93-690 of the bovine channel), the two share $93 \%$ amino acid identity, with most differences being conservative substitutions. Two single amino acid insertions are required to align the two sequences.

An unexpected finding is the presence of an Alu repetitive element within the $5^{\prime}$ untranslated region of the human mRNA. This element appears to be encoded in the genome as one (or more than one) separate exon that becomes intercalated between two preexisting exons in the mature transcript. This unusual 


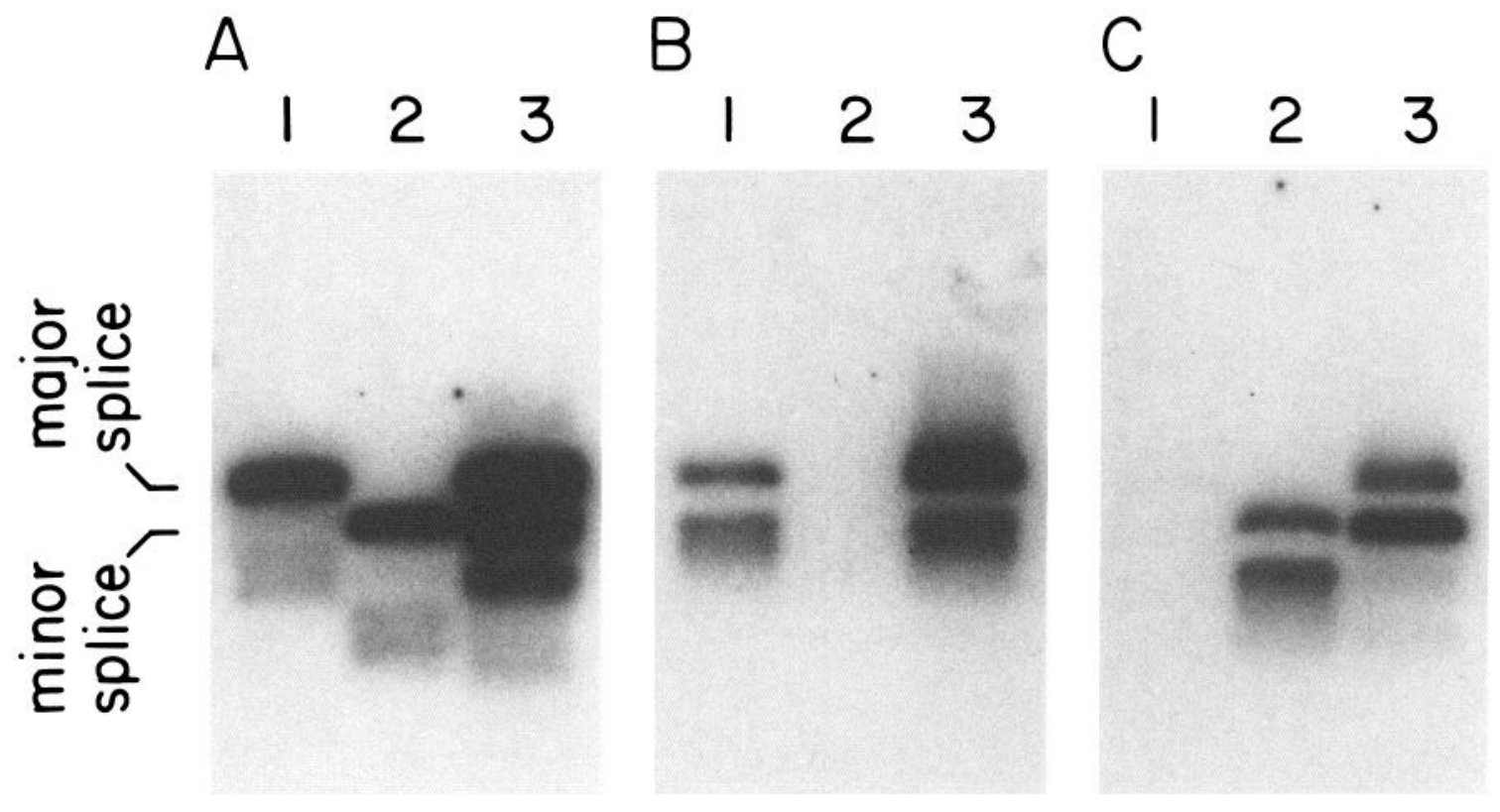

Figure 5. Blot hybridization of PCR products derived from alternatively spliced transcripts. $A-C$ show identical blots of PCR products separated by alkaline agarose gel electrophoresis. All PCR products were amplified using primers JM 52 and JM14, which prime in exons 5 and 10 , respectively. Lanes 1 and 2, control PCR products derived from amplification of cloned full-length and alternatively spliced cDNA templates, respectively. Lane 3 , PCR products derived from amplification using first strand human retina cDNA as template. $A$, Probed with JM53, located in exon $10,5^{\prime}$ of PCR primer JM14, and therefore common to both major and minor spliced forms. B, Probed with JM23, located within alternatively spliced exon 8. $C$, Probed with JM51, a 20 -mer that spans the alternative exon 7-exon 9 splice junction. The source of the lower molecular weight species in all lanes is presumed to be incomplete or aberrant PCR products. The higher molecular weight band in lane C3 may represent a splicing product different from the two described here.

sequence arrangement may have some effect on channel production. Given that many Alu elements are present in cellular RNA - in both orientations within $3^{\prime}$ untranslated regions and in RNA polymerase III transcripts in the orientation opposite

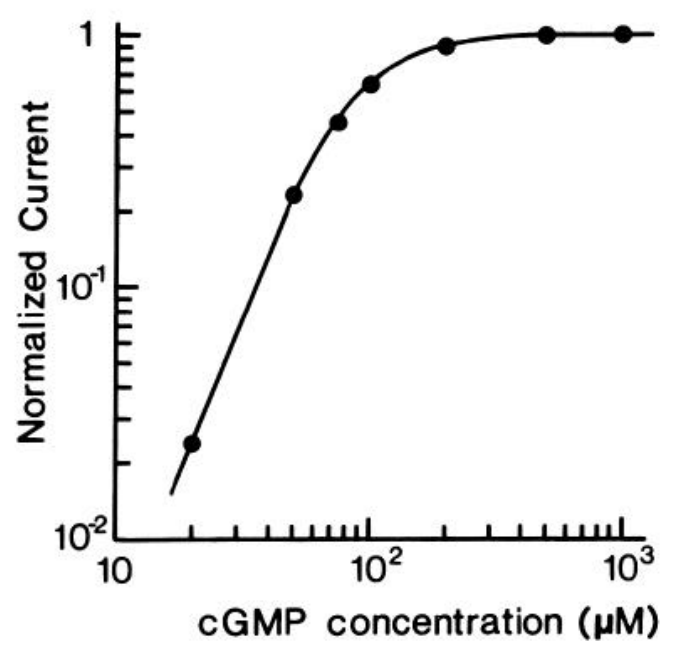

Figure 6. Dose-response relation between membrane current activation and cGMP concentration measured on an excised membrane patch from a 293 cell transfected with the cloned cDNA. Ringer's solution without divalent cations was present on both sides of the membrane, and the transmembrane potential was held at $+40 \mathrm{mV}$. The smooth curve is the Hill equation, $j / j_{\max }=C^{n} /\left[C^{n}+K_{1 / 2}^{n}\right]$, where $C$ is the cGMP concentration, $K_{1 / 2}$ is the cGMP concentration that produces half-maximal activation, and $n$ is the Hill coefficient. The fit to the data was made with $K_{1 / 2}=80 \mu \mathrm{M}$ and $n=2.7 . j_{\max }$ in this experiment was 445 pA. to that found in the cGMP-gated channel-it is reasonable to suppose that RNA heteroduplexes may form in vivo between the Alu sequence in the cGMP-gated channel mRNA and other Alu sequences of complementary strandedness. It is reasonable to suppose that such heteroduplexes might alter the stability and/or translational efficiency of the mRNA.

The arrangement of coding region exons in the human cGMPgated channel shows an intriguing asymmetry: the amino-terminal 229 amino acids are encoded by seven exons, whereas the carboxy-terminal 457 amino acids are encoded by a single large exon. This arrangement is reminiscent of the pattern observed among intron-containing genes in the yeast Saccharomyces cerevisiae, in which most introns occur near the $5^{\prime}$-ends of transcription units. Fink (1987) has suggested that this pattern may reflect loss of introns by homologous recombination with incomplete reverse transcripts of mRNA molecules. An alternative scenario to account for the observed gene structure would be that the large 3 '-proximal exon is directly descended from an ancestral gene, whereas the small 5'-proximal exons evolved more recently. This scenario fits well with the observation that five of the six small internal coding region exons are multiples of three nucleotides in length. These five exons could have intercalated into a preexisting channel gene without changing the reading frame.

The pattern of exon lengths described above prompted us to look for differentially spliced variants in the $5^{\prime}$ coding region of the mRNA. Thus far, one variant has been identified in which exon 8 is absent, resulting in an in-frame deletion of 36 codons. The exon 8 donor and acceptor splice junction sequences are among the most divergent from the consensus (Table 1), suggesting that the splicing variant could result from a lower efficiency of RNA cleavage adjacent to this exon. Exon 8 encodes 

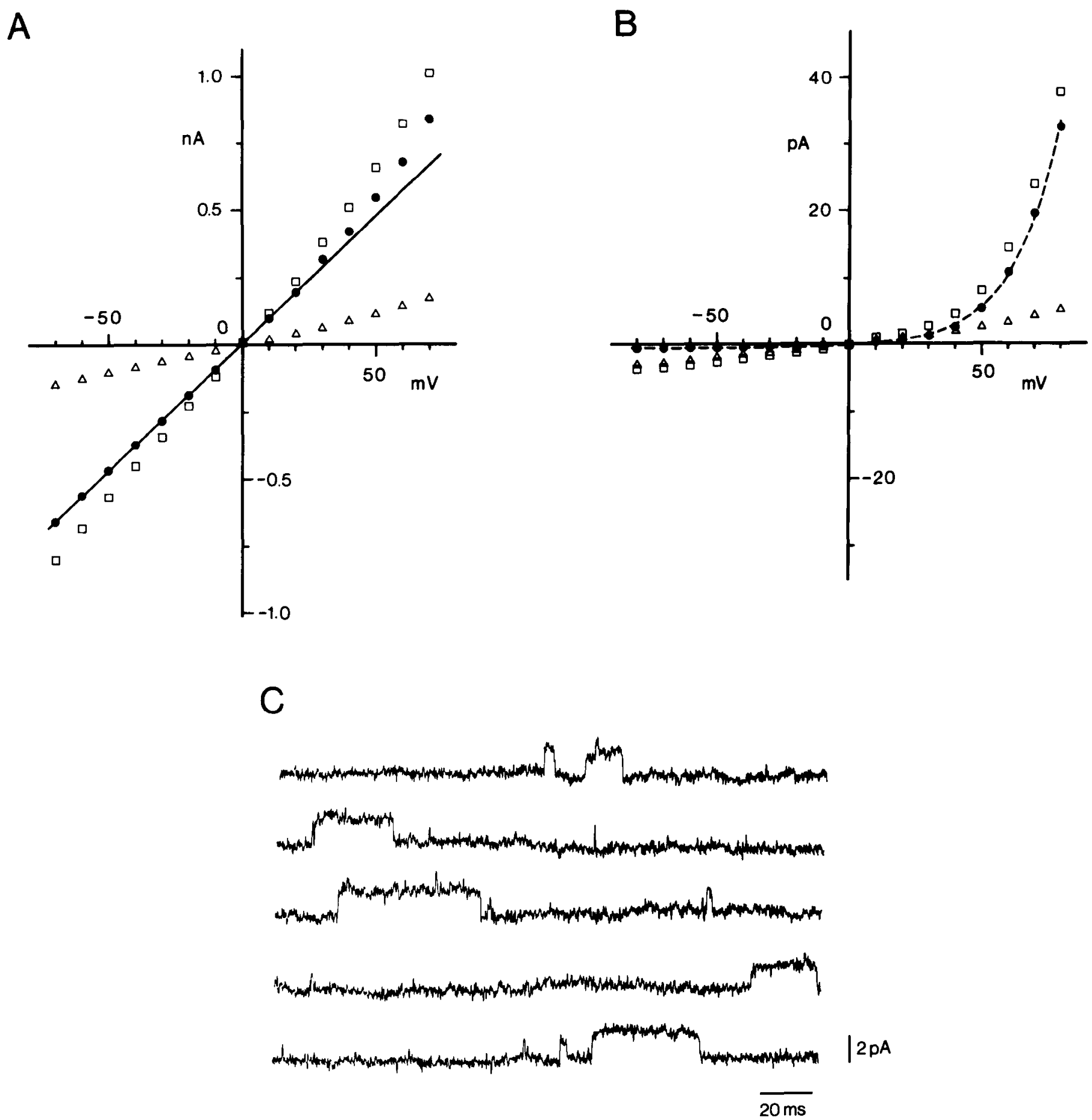

Figure 7. $A$ and $B$, Steady-state current-voltage relations for the expressed channel in the absence and the presence of divalent cations. Two separate patches are shown, with $1 \mathrm{~mm}$ cGMP in both cases. The experiment consisted of making $1 \mathrm{sec}$ voltage pulses at $\pm 10 \mathrm{mV}$ increments from a holding potential of $0 \mathrm{mV}$. The current at each voltage was measured at the end of the voltage pulse. Open triangles, Relation obtained in the absence of divalent cations; open squares, relation obtained in the presence of $1 \mathrm{mM}$ cGMP; solid circles, difference between the preceding two conditions, giving the relation for the cGMP-gated channel. In $A$, Ringer's solution without divalent cations was present on both sides of the membrane patch. A straight line is fitted to the points at negative voltages and extrapolated to positive voltages. In $B$, Ringer's solution with divalent cations was present in the pipette, and Ringer's solution without divalent cations was present in the bath solution. Symbols have the same significance as in $A$. The broken curve is a scaling of the equation $j(V)=\exp [(V-4) / 17.5]-1$, where $V$ is membrane potential in $\mathrm{mV}$. $C$, Singlechannel openings recorded from another patch. Ringer's solution without divalent cations was present on both sides of the membrane. The transmembrane potential was held at $+60 \mathrm{mV}$ in the presence of $5 \mu \mathrm{M}$ cGMP.

a stretch of amino acids that constitutes a proposed first transmembrane domain of the channel (Kaupp et al., 1989). Transfection of the variant cDNA did not produce functional cGMPgated channels (see Results). This suggests that a homooligomer formed from the protein encoded by this variant RNA is either unstable or not functional (or both). The possibility that a heterooligomeric complex could form between this variant and the major protein species remains to be examined. 


\section{References}

Bowes C, Li T, Danciger M, Baxter LC, Applebury ML, Farber DB (1990) Retinal degeneration in the $r d$ mouse is caused by a defect in the beta subunit of rod cGMP-phosphodiesterase. Nature 347:677680.

Britten RJ, Baron WF, Stout DB, Davidson EH (1988) Sources and evolution of human Alu repeated sequences. Proc Natl Acad Sci USA 85:4770-4774.

Chomczinski P, Sacchi N (1987) Single step method of RNA isolation by acid guanidinium thiocyanate-phenol-chloroform extraction. Anal Biochem 162:156-159.

Dhallan RS, Yau K-W, Schrader KA, Reed RR (1990) Primary structure and functional expression of a cyclic nucleotide-activated channel from olfactory neurons. Nature 347:184-187.

Dryja T, McGee TL, Reichel E, Hahn LB, Cowley GS, Yandell DW, Sandberg MA, Berson EL (1990) A point mutation of the rhodopsin gene in one form of retinitis pigmentosa. Nature 343:364-366.

Dryja TP, Hahn LB, Cowley GS, McGee TL, Berson EL (1991) Mutation spectrum of the rhodopsin gene among patients with autosomal dominant retinitis pigmentosa. Proc Natl Acad Sci USA 88:93709374

Farrar GJ, Kenna P, Jordan SA, Kumar-Singh R, Humphries MM, Sharp EM, Sheils DM, Humphries P (1991) A three base pair deletion in the peripherin- $R D S$ gene in one form of retinitis pigmentosa. Nature 354:478-480.

Fesenko EE, Kolesnikov SS, Lyubarsky AL (1985) Induction by cyclic GMP of cationic conductance in plasma membrane of retinal rod outer segments. Nature 313:310-313.

Frischauf A-M, Lehrach H, Poustka A, Murray N (1983) Lambda replacement vectors carrying polylinker sequences. J Mol Biol 170: 827-842.

Gorman CM (1985) High efficiency gene transfer into mammalian cells. In: DNA cloning, Vol II (Glover DM, ed), pp 143-190. Oxford: IRI.

Gorman CM, Gies DR, McCray G (1990) Transient production of proteins using an adenovirus transformed cell line. DNA Protein Eng Technol 2:3-10.

Haynes LW, Yau K-W (1985) Cyclic-GMP-sensitive conductance in outer segment membranes of catfish cones. Nature 321:66-70.

Haynes LW, Yau K-W (1990) Gating kinetics of cGMP-activated channel in catfish cones. Biophys J 57:366a.

Jan LY, Jan YN (1990) A superfamily of ion channels. Nature 345: 672.

Jurka J, Smith T (1988) A fundamental division in the Alu family of repeated sequences. Proc Natl Acad Sci USA 85:4774-4778.

Kajiwara K, Hahn LB, Mukai S, Travis GH, Berson EL, Dryja TP (1991) Mutations in the human retinal degeneration slow gene in autosomal dominant retinitis pigmentosa. Nature 354:480-483.

Kamb A, Tseng-Crank J, Tanouye MA (1988) Multiple products of the Drosophila Shaker gene may contribute to potassium channel diversity. Neuron 1:421-430.

Karpen JW, Zimmerman AL, Stryer L, Baylor DA (1988) Gating kinetics of the cGMP-activated channel of retinal rods: flash photolysis and voltage-jump studies. Proc Natl Acad Sci USA 85:12871291

Kaupp UB, Niidome T, Tanabe T, Terada S, Bonigk W, Stuhmer W, Cook NJ, Kangawa $K$, Matsuo $H$, Hirose $T$, Miyata $T$, Numa $S$ (1989) Primary structure and functional expression from complementary DNA of the rod photoreceptor cGMP-gated channel. Nature 342:762-766.

Ludwig J, Margalit T, Eismann E, Lancet D, Kaupp UB (1990) Primary structure of a cAMP-gated channel from bovine olfactory epithelium. FEBS Lett 270:24-29.
Lurhing H, Kaupp UB (1989) Study of the mammalian cGMP-gated channel from excised membrane patches. Biophys J 55:377a.

Molday RS, Molday L, Dose A, Clark-Lewis I, Illing M, Cook NJ, Eismann E, Kaupp UB (1991) The cGMP-gated channel of the rod photoreceptor cell: characterization and orientation of the amino terminus. J Biol Chem 266:21917-21922.

Mount SM (1982) A catalogue of splice junction sequences. Nucleic Acids Res 10:459-472.

Nakamura T, Gold GH (1987) A cyclic nucleotide-gated conductance in olfactory receptor cilia. Nature 325:442-444.

Nakatani K, Yau KW (1988) Calcium and magnesium fluxes across the plasma membrane of the toad rod outer segment. J Physiol (Lond) 395:695-729.

Nathans J, Hogness DS (1983) Isolation, nucleotide sequence, and intron-exon arrangement of the gene encoding bovine rhodopsin. Cell 34:807-814.

Nathans J, Thomas D, Hogness DS (1986) Molecular genetics of human color vision: the genes encoding blue, green, and red pigments. Science 232:193-202.

Pittler SJ, Baehr W (1991) Identification of a nonsense mutation in the rod photoreceptor cGMP phosphodiesterase beta-subunit gene of the $r d$ mouse. Proc Natl Acad Sci USA 88:8322-8326.

Pugh EN, Cobbs WH (1986) Visual transduction in vertebrate rods and cones: a tale of two transmitters, calcium and cyclic GMP. Vision Res 26:1613-1643.

Sambrook J, Fritsch EF, Maniatis T (1989) Molecular cloning: a laboratory manual. Cold Spring Harbor, NY: Cold Spring Harbor Laboratory.

Schwarz TL, Tempel BL, Papazian DM, Jan YN, Jan LY (1988) Multiple potassium-channel components are produced by alternative splicing at the Shaker locus in Drosophila. Nature 331:137-142.

Shows TB, Brown JA, Haley LL, Byers MG, Eddy RL, Cooper ES, Goggin AP (1978) Assignment of the beta-glucuronidase structural gene to the pter-q22 region of chromosome 7 in man. Cytogenet Cell Genet 21:99-104.

Shows TB, Sakaguchi AY, Naylor SL (1982) Mapping of the human genome, cloned genes, DNA polymorphisms, and inherited disease. In: Advances in human genetics, Vol 12 (Harris H, Hirschorn K, eds), pp 341-452. New York: Plenum.

Shows TB, Eddy RL, Haley L, Byers M, Henry M, Fujita T, Matsui H, Taniguchi T (1984) Interleukin 2 (IL2) is assigned to human chromosome 4. Somat Cell Mol Genet 10:315-318.

Sommer B, Keinanen K, Verdoorn TA, Wisden W, Burnashev N, Herb A, Kohler M, Takagi T, Sakmann B, Seeburg P (1990) Flip and flop: a cell-specific functional switch in glutamate operated channels of the CNS. Science 249:1580-1585.

Stryer L (1986) Cyclic GMP cascade of vision. Annu Rev Neurosci 9:87-119.

Sung C-H, Davenport CM, Hennessey JC, Maumenee IH, Jacobson SG, Heckenlively JR, Nowakowski R, Fishman G, Gouras P, Nathans J (1991) Rhodopsin mutations in autosomal dominant retinitis pigmentosa. Proc Natl Acad Sci USA 88:6481-6485.

Timpe LC, Jan YN, Jan LY (1988) Four cDNA clones from the Shaker locus of Drosophila induce kinetically distinct A-type potassium currents in Xenopus oocytes. Neuron 1:659-667.

Travis GH, Brennan MB, Danielson PE, Kozak CA, Sutcliffe JG (1989) Identification of a photoreceptor-specific mRNA encoded by the gene responsible for retinal degeneration slow $(r d s)$. Nature 338:70-73.

Wood WJ, Gitscher J, Lasky LA, Lawn RM (1985) Base-compositionindependent hybridization in tetramethylammonium chloride: a method for oligonucleotide screening of highly complex gene libraries. Proc Natl Acad Sci USA 82:1585-1588.

Yau K-W, Baylor DA (1989) Cyclic GMP activated conductance of retinal photoreceptor cells. Annu Rev Neurosci 12:289-327. 